\title{
Notas sobre la historia ecológica de América Latina*
}

\section{INTR'ODUCGTON}

E1 término expoliación está íntimamente ligado a la historia postcolombina de América Latina. Con esta afirmación estamos indicando que antes del descubrimiento la situación era diferente.

Antes y después de Colón es el contraste entre la cultura de los pueblos que habían aprendido a vivir ecológicamente sanos versus un desarrollo "minero" extractivo y deteriorante que no se preocupaba de la conservación de los recursos.

Los pueblos precolombinos no vivieron en equilibrio con la naturaleza sino que la artificialización, entendiendo la relación hombrenaturaleza en función de su aprehensión cognoscitiva basada en la investigación de ella.

En este relato planteamos lo que a nuestro juicio son las ilustraciones más relevantes del comportamiento ecológico de las culturas precolombinas. Las civilizaciones hidráulicas basadas en la disponibilidad excesiva cle agua, muestra de un complejo y acabado conocimiento bioecológico, la civilización Maya, poliproductores tanto agrícolas como silvo-ganaderos y la organizada civilización Inca, en donde predominaron las tecnologías de zonas áridas y semiáridas.

Es evidente que después del descubrimiento se constatan varios períodos bien diferenciados. Hemos dividido esta época en dos grandes períodos: en primer lugar, la conquista y la colonia y en segundo lugar el período que va desde la formación de las nuevas naciones independientes hasta principios del presente siglo. Más allá no hemos querido avanzax por la complejidad creciente del proceso de desarrollo.

En el período de la conquista y colonia hemos destacado su característica fundamental: la aculturación a toda čosta y la ocupación del territorio con sus consecuencias en la alteración de los ecosistemas.

El período "independiente" indudablemente nació con un esfuerzo

* Trabajo presentado al Seminario sobre Estilos de Desarrollo y Medio. Ambiente en América Latina, organizado conjuntamente por la CEPAL y PNUMA, dul 19 al 23 cie noviembre de 1979 . 
de reestructuración del poder en función del control de los recursos naturales. Aquí el rol internacional de los nuevos Estados condicionó tanto la estructura productiva como las formas de uso de los recursos. Este análisis nos muestra, a su vez, las principales facetas de la acción antrópica en los ecosistemas.

Con estas notas queremos destacar la importancia del enfoque ecológico en la historia de los países latinoamericanos. Creemos que no se le ha dado, o en algunos casos no se le ha querido dar, la importancia debida.

\section{LA INTEGRAGION MEDIO AMIBIENTAL DE LAS GULTURAS DEL PERTOD'O PRECOLOMBINO}

La experiencia y el conocimiento de la naturaleza de los habitantes prehispánicos del continente se había traducido en formas de control y adopción con relación al ambiente, las que se perdieron en parte por la destrucción de estas civilizaciones y por la aculturación sufrida.

El conocimiento basado en la observación de los procesos de la naturaleza unido a una exacta evaluación de los efectos de la acción humana, hacen deducir que las civilizaciones precolombinas tenían incorporadas en su acervo cultural concepciones de ecología empírica. Ello no quiere decir que no hayan afectado el medio ambiente. Algunas civilizaciones decayeron e incluso desaparecieron por el agotamiento de los recursos de la tierra. Factores naturales y particularmente de relaciones sociales condicionaron estos hechos, pero en términos generales se puede afirmar que las relaciones hombre-naturaleza fueron mucho más armónicas. Esta armonía no se refiere al "equilibrio" del hombre como parte del ecosistema, sino a la artificialización de él que hizo el indígena, a su mayor productividad y a su conservación. Los grados de artificialización fueron diversos según el grupo cultural, fluctuando desde simples recolectores hasta civilizaciones altamente desarrolladas.

El desarrollo de las civilizaciones se estructuró en torno al recurso básico: el agua. En relación a este recurso, hubo en América Latina dos tipos de civilizaciones hidráulicas: aquellas que manejaron excedentes de agua en ambiente anegadizo (Isla de Marajó en Brasil, Ilanos de Moxos en Bolivia, llanos de San Jorge en Colombia, Suriname, Guenca del río Guayas en Ecuador, lago Titicaca y lago de Texcoco en México) y las que regaron en ambiente árido, llamada andina.

Las culturas de áreas regadizas, con la sola excepción de la agricultura del lago Texcoco $y$ del lago Titicaca, habían desaparecido 
a la llegada del hombre blanco y sólo quedaban sus restos de camellones, sobre los cuales cultivaban. El equipo tecnológico que se conserva es el del cultivo de chinampa en México. La otra civilización hidráulica, de riego, andina, es la que más ha sido estudiada porque florecía a la llegada de los españoles. Hubo, además, una civilización de policultores que manejaron la selva: la cultura maya de Yucatán.

A continuación se analizarán algunas características relevantes de las civilizaciones de manejo de excedentes de agua, después la civilización policultora y silvícola Maya y, por último, la civilización Inca.

a) Civilizaciones de manejo de excedentes de agua.

El conocimiento científico de estas civilizaciones en América del Sur comienza en 1879 cuando Derby ${ }^{1}$ descubrió camellones en la isla de Marajó, en Brasil. En 1916, y a miles de kilómetros de la boca del Amazonas, Erland Nodenskiöld ${ }^{2}$ describió el complejo de drenaje y camellones de los Ilanos de Moxos, en Bolivia. La cultura de pantanos de Moxos volvió a examinarse en 1962-1966 por Denevan ${ }^{3}$ y Plafker, y estructuras de camellones fueron estudiadas en el Norte de Colombia ${ }^{5}$, en Suriname y en Ecuador.

Las amplias áreas de América Latina con excedentes đe agurs fueron utilizadas para la producción agrícola. De todos los sistemas descubiertos, es el de la Chinampa de México el que más interesa destacar por sus posibilidades tecnológicas, su racionalidad ecológica y por ser el único que no había desaparecido a la llegada del europeo.

ta racionalidad ecológica del sistema chinampa consiste en manipular simultáneamente el ambiente acuático y el terrestre. Del primero se obtiene agua, vegetación flotante y arraigada para construir suelos, y peces; del segundo 2 a 3 cosechas por año de los cultivos principales (maíz, frijol) y madera de los árboles fijaclores del borde del canal.

IDerby, O. A. The artificial mounds of the island of Marajo, Brazil. Amer. Nat., 13, pp. 224-229, 1879.

${ }^{2}$ Nordenskiöld, E. Die Ampassung der Indianer an die Terhaltnisse in den Uberschwenmungsgehieten in Südamerika. IMer, 36: pp. 135-138, 1916.

${ }^{3}$ Denevan, W. M. The aboriginal culture geography of the llanos of Mojos, in Northeastern Bolivia. Amer. Antig. 28: pp. 550-545, 1966.

"Plafker, G. Observations on Archaeological remains in Northeastern Bolivia. Amer. Antig. 28: pp. 372-379, 1963.

SParsons, J. y Bowen, W. Ancient Ridges Fields of the San Jorge River Floodplain. Colombia Geogr. Rev. 56: pp. 317-343, 1968. 
La chinampa mexicana se caracteriza por un proceso de creación de suelo orgánico sobreelevado como camellón en un ambiente acuático, con una técnica que usa ramas, lodo de fondos de pantano y abono orgánico. Incluye un proceso especial de construcción de almácigos, donde cada plántula es transplantada con su pan de tierra que incluye suficientes nutrientes para que llegue a la madurez productiva (los llamados chapines). Se requieren técnicas de control biológico de malezas con "cultivos de entretenimiento", es decir, plantados para que sean consumidos por las plagas, de control de plagas por cobertura con paja de los almácigos, construcción, fijación y mantenimiento de canales, alta diversidad de cultivos, conocimiento de cortinas rompevientos, manejo de fauna acuática (pesca planificada). El almácigo y el sistema de transplante por chapines (cubitos de suelo de $125 \mathrm{~cm}^{3}$ ), representan un sofisticado y complejo paso tendiente a transplantar con sistema radicular íntegro cada ejemplar con su banco de nutrientes y a controlar enfermedades virosas, descartando plantas enfermas.

Las civilizaciones de manejo de excedentes de agua como la descrita permitieron una densidad de población rural de unos 150 habitantes $/ \mathrm{km}^{2}$, en superficies estimadas en 30.000 hectáreas en San Jorge, en Colombia, y 82,000 hectáreas en el lago Titicaca. Además, sustentaron en parte metrópolis hasta 500.000 habitantes (Tenochtitlan).

El sistema agrícola autosuficiente fue intensivo en mano de obra llegándose a ocupar 20 jornadas diarias por hectárea. La unidad familiar con cierto excedente comercializable se estima que era de $800 \mathrm{~m}^{2}$.

\section{b) Civilización Maya.}

El desarrollo de esta cultura se remonta de 600 a 300 años antes de Cristo, aunque el apogeo del primer imperio se estima que haya durado hasta el 300 ó 900 d.C. ${ }^{6}$. Este imperio se desarrolló en la región de los bosques húmedos, pero se afirma que su sistema agrario se habría desarrollado en las tierras altas de Guatemala: Abarcaron hasta la selva del Yucatán. Constituyeron un estilo prehispánico adaptado como ningún otro al manejo del bosque y puede Ilamársele agrosilvícola.

Los mayas fueron "policultores" $y$, además de la tecnología agrí-

oMorley, S. G. La civilización Maya, Fondo de Cultura Económica, México D. F. 
cola andina (terrazas, riego), se los puede considerar una cultura basada en un profundo conocimiento del manejo de la selva: desde rotación y descanso de la tierra en el sistema de cultivo itinerante, hasta la tala selectiva que dejaba árboles útiles (árbol del chicle, ramón, cacao, ceiba, anona, chicozapote) .

La agricultura la hacian en pequeñas abras, y de la selva manejada vecina sacaban medicinas, alimentos y materiales de construcción.

Todo el sistema de manejo de la selva y de la agricultura itinerante -se basaba en el conocimiento del ciclo fenológico de ciertos árboles. Por ejemplo, la tumba se hacía cuando florecían el Cochlospermum sp; la quema cuando sus frutos se abrían. Además practicaron la horticultura y fruticultura en sistema de varios pisos.

Sobre las causas de la decadencia de este imperio hay varias hipótesis, una de las cuales se basa en el agotamiento de las tierras y otra al efecto de modificaciones climáticas. En todo caso las hipótesis basadas en el agotamiento no se compadecen con las cualidades conservacionistas que se le atribuyen a los mayas.

Alrededor del año 1.000 d.C. se produjo el renacimiento del imperio, hasta el siglo $\mathrm{xv}$, en que continuas guerras lo hicieron dividirse en pequeños estados. Este segundo imperio fundamentó sus sistemas agrícolas en los conocimientos de sus antecesores.

Parece ser que el Nuevo Imperio Maya influyó en la civilización de los toltecas. El impresionante pero efímero Imperio Tolteca se basaba en los tributos exigidos a sus conquistados y en un sistema de explotación agrícola. En el siglo xur se desmoronó el imperio y dio paso a la cultura azteca.

\section{c) Civilización Inca.}

En América del Sur el Imperio Inca creó una civilización de notables relieves cuyas características merecen especial mención. El auge del Imperio se ubica desde el quinto Inca (Capac Yupanqui, 1276-1321) hasta la conquista española.

Dado que a la llegada de Ios españoles el Imperio Inca se encontraba en su apogeo, se pudo obtener mayores antecedentes de sus sistemas culturales. Por esta razón, a continuación se tratará con más detalles los aspectos relevantes de los sistemas agrarios de esta cultura. 
En primer lugar es necesario hacer luces sobre la cantidad de habitantes de esta civilización. Como afirma Ponce Sangines "el tema concerniente al monto de la población es objeto de controversia". Las cifras fluctúan notablemente entre 3 y 32 milloness, pero la mayoría de los autores ha dado cifras que varían entre 10 y 16 millones. Un exhaustivo estudio realizado en 1955 calcula que a fines del siglo $\mathrm{xv}$ la población del imperio era de 12 millones ${ }^{9}$.

La civilización Inca, al igual que la Maya, operó en distintas ecoregiones, en distintos pisos térmicos y en distintas subregiones de humedad dentro de cada piso térmico. Pese a que esta civilización ocupó espacios muy diferentes la organización del imperio fue uniforme. Su economía, básicamente agrícola, se fundaba en un "comunismo agrario rigurosamente aplicado, que regulaba el derecho de los indios a las tierras, así como sus faenas e impuestos; por medio de una colonización metódica se conseguía que se cultivaran comarcas anteriormente eriales"10.

El operar en distintas regiones diferenció fundamentalmente al Imperio Inca de las civilizaciones de manejo de excedentes de agua, que operaron en un clima homogéneo e hicieron poliproducción en cada predio. Aquí las posibilidades fueron tan variadas que los cultivos básicos exan el maíz en las áreas de menos altura; la papa, la oca (Oxalis Tuberosa), la quinua (Chenopodium quinoa), ulluco, cañihua, tarhui, en las zonas altas.

En las áreas de la costa, además de maíz, al que se le sacaban dos cosechas al año, se cultivaba la yuca (Mamihot utilissima) y la batata o camote (Beteta edulis).

El cultivo industrial base era el algodón. Habían además, en Ia parte selvática húmeda, importantes plantaciones de coca (Erythooxylon coca) para uso de todo el imperio.

El punto central es que esta civilización, al operar en un espectro ambiental muy diverso, tuvo como condicionantes ambientales la

TPonce Sangines, Garlos. La cultura nativa, su entronque y sus rasgos principales. Instituto Boliviano de Cultura. La Paz, 1975.

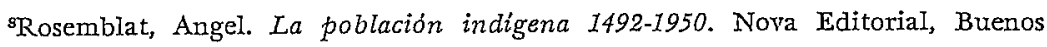
Aires, 1954.

'Puga, Mario. Los incas (sociedad y estado). Ediciones Centauro, México, 1955.

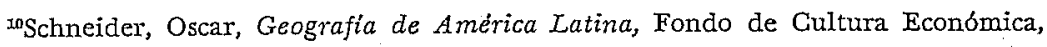
México, 1965. 
energía del relieve y la escasez de agua. Pero pese a la diversidad de condiciones los incas nunca consiguieron dominar la selva ${ }^{11}$.

Un hecho notable del imperio incásico fue la tecnología usada con respecto al suelo y al agua. Dada la aridez del clima, se aplicaba riego en muchas áreas, lo que se podía realizar por las obras de acumulación y captación a nivel de conducción del agua y por tecnologías en los sistemas de riegos a nivel predial.

En relación al suelo, dada la geomorfología existente, construían terrazas con el objeto de evitar el cultivo en pendiente. Además en la costa una práctica usual era abonar con productos del mar o con estiércol de camélidos. En el interior, debido a que no existía abono y el estiércol se usaba para combustible, los suelos eran rotados y se Ies dejaba descansar.

Es importante destacar cuatro aspectos sobresalientes del estilo de desarrollo prehispánico de los imperios agrarios, tomando como ejemplo el incaico, aspectos que están relacionados con la conservación y racionalización del uso de los recursos.

$\mathrm{El}$ primero es la eficiencia con que articularon distintas ecorregiones, es decir, zonas que esencialmente tienen las mismas condiciones climáticas para producción animal y vegetal, obteniendo alta diversidad de productos, y compensando las estaciones desfavorabies de una con los productos de otras ecorregiones. Esto obligó a desarrollar una elaborada tecnología de construcción y manejo de un sistema de carreteras de más de $10.000 \mathrm{~km}$ que ligaban, por ejemplo, Mendoza y Santiago con Tumbez, Cochabamba y Lacatunga12.

El segundo se relaciona con la dinámica organizativa en la agricultura, en términos de una relación dialéctica entre los componentes individuales mínimos (las unidades familiares) y la comunidad compuesta de éstos en conjunto que administraba el territorio usufructuado por ellos cómo una unidad13. En realidad, el tratamiento científico que daban los Incas para resolver sus problemias de producción y

${ }^{11}$ Hardvy, Jorge Enrique. Ciudades precolombinas. Ediciones Infinito. Buenos Aires, 1964.

${ }^{13 H a g e n ~ V . ~ W . ~ s o s t i e n e ~ q u e ~ l a ~ c a r r e t e r a ~ d e ~ l a ~ c o s t a ~ m e d f a ~} 4.050 \mathrm{~km}$ y la de la sierra 5.180. Ver Hagen, Víctor Wolfang von. Los reinos americanos del sol. Segunda Edición. Editorial Labor. Barcelona, 1968.

${ }^{13}$ Mayer, E. Tenencla y control comilnal de la tierra. Caso de Laraos (Yauyus). Pontificia Universidad Gatólica, Lima, Perú, 1977. 
reproducción, según Earls ${ }^{14}$ combinaba: a) una ciencia de orden de sistemas en general; b) una ciencia "termodinámica" de las transferencias eficientes de energías entre la sociedad y la naturaleza; c) una ciencia de comunicaciones que empleaba mecanismos sofisticados para establecer equivalencias entre diversas zonas ecológicas de producción, y d) una astronomía que servía no sólo para las mediciones propias de su área del saber, sino de organización científica de la sociedad en general.

El tercer aspecto tiene relación con la orientación y regulación colectiva de la producción andina. A este respecto, Mayer ${ }^{15}$, señala: "Lo que ocurre en realidad es un constante proceso de interactuación entre el individuo y la comunidad en la cual las reglas de uso surgen de un consenso común de que ésta es la mejor manera de organizar la producción, la posterior disconformidad de algunos que se organizan para contravenir y abiertamente cuestionar estas reglas, para luego elaborar un nuevo concurso que incorpore los puntos propuestos para este grupo, y así sucesivamente van conjugándose intereses individuales con los comunales en el normal proceso político del manejo de los recursos comunales".

Este proceso dialéctico de regulación y readopción del uso de los recursos sirvió como base para estructurar un sistema que maximizase los recursos disponibles y los conservase. Todo esto "dentro" de la comunidad; los investigadores poco aportan a las fuerzas de trabajo dispuestas para las tierras del Inca y para las sacerdotales tierras del sol, así como al estudio de los flujos de excedentes desde la comunidad a la clase dominante y la forma de regulación de estos excedentes. Posiblemente explorar estos flujos, sobre todo en los pueblos dominados, explicaría el sobreuso del suelo que hicieron determinadas comunidades.

El cuarto aspecto que se desea destacar, es la tecnología empleada, que tendería $\mathrm{a}^{\mathrm{IB}}$ :

${ }^{14}$ Earls, J. La coordinación de la producción agricola en el Tawentisuyu. Primex Congreso Internacional de Cultivos Andinos, Universidad Nacional San CristóbalHuamenga / IICA, Ayacucho, Perú, octubre de 1977.

IMayer, E. Aspectos colectivos de la producción andina, en Primer Congreso Internacional de Cultivos Andinos, Universidad San Cristóbal-Huamanga/uaA, Ayacucho, Perú, octubre de 1977, p. 33.

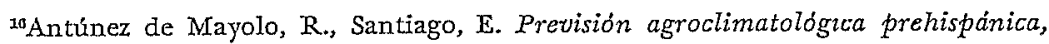
en Primer Congreso Internacional de Cultivos Andinos. Universidad Nacional San Cristóbal-Huamanga/rraA. Ayacucho, Perú, octubre de 1977, p. 155 . 
- selección de cultivares;

- adecuación fisicoquímica del suelo a cultivar;

- uso de fertilizantes;

- creación de herramientas que permitían mejorar y conservar la estructura del suelo;

- prácticas de riego;

- prácticas de laboreo destinadas a evitar la evaporación y erosión del suelo;

- tratamiento bioquímico de las semillas para obtener una mayor cosecha;

- tratamiento de las semilias para evitar su infección;

- protección fitosanitaria mediante cultivos asociados o intercalados;

- laboreo intenso de cultivo;

- técnicas de previsión meteorológica y del clima, que incluía la determinación de la época de siembra y selección de variedades.

De estas tecnologías, algunas eran dominadas en tal profundidad que es necesario una mención especial. Las previsiones climáticas para condicionar las fechas de cultivos y cosechas, demostraron que los Incas tenían un acabado sistema basado en la tradición y en la observación científica de la naturaleza.

A este respecto, "el sistema inca de previsión del clima se sustentó en siete grupos de variables, con intensificadores y restrictores"17. Las variables del tiempo como calor, lluvia, tormentas, nubes y vientos en función de sus formas, colores, etc., fueron usadas para las previsiones inmediatas. Otras variables se refirieron al comportamiento del mar, a las fuerzas cósmicas (brillo de las estrellas, etc.) y al comportamiento de la fauna (hoy, etología). Además las distintas reacciones de la flora autóctona eran minuciosamente observadas (hoy denominado comportamiento fenológico) .

El otro aspecto tecnológico relevante es el relacionado con las fuentes alimentarias y la nutrición, aspecto ligado a la estabilidad de los ecosistemas. En efecto, el poblador prehispánico dispuso de una mayor variedad de alimentos que los que actualmente se cultivan, pero, no obstante, utilizó un alto consumo de plantas silvestres y capturó la fauna en forma planificada, lo que influyó en la conservación y mantenimiento de ella (vicuñas y guanacos) al mismo tiempo de abastecer de proteínas al poblador.

Las prácticas alimentarias eran muy completas y consultaban conservación, ablactación y selección en base al poder nutritivo. Sorprende

${ }^{17}$ Antúnez de Mayolo, R., Santiago, E., Previsión agroclimática prehispánica, op. cit., p. 156. 
el crecimiento de cultivos o plantas cuyo poder nutritivo era muy alto. Además, a ella sumaban un conocimiento fisiológico avanzado. Al respecto Antúnez de Mayolo ${ }^{18}$ afirma que la comprobación en cuanto al rendimiento energético puede ser sencilla, pero "el conocer los efectos de respuestas a los alcaloides, esteroides y otros principios activos contenidos implicaba un conocimiento fisiológico profundo".

El mismo autor incluye una tabla donde calcula la dieta inca per capita, obteniendo la cantidad de 2.420 cal, muy superior a la meta UNMSM de 2.183. Aunque no se detalla la metodología empleada, lo que lleva a considerar un margen de error, la cifra tiende a confirmar lo que es usual escuchar corrientemente: que los indígenas del Imperio Inca tenían una alimentación superior a los del actual mundo civilizado del área altiplánica.

En resumen, lo que modeló el estilo del desarrollo incásico, fue una poliproducción integrada de distintas ecorregiones, la posibilidad del establecimiento de un sistema social con clases de especialistas de dedicación exclusiva no ligados directamente a la producción de alimentos (sacerdotes, artesanos, mineros) y una organización del universo productivo en un ciclo anual, dentro del cual el calendario agrícola y la caza, pesca y recolección planificadas, eran las facetas más importantes.

El estilo inca puede resumirse en intensivo de mano de obra, de alta diversidad productiva por ecorregiones, y de ajuste racional a la oferta de recursos con una combinación de producción agrícola intensiva, caza, pesca y recolección ${ }^{19}$.

Estos antecedentes dados sobre las poblaciones prehispánicas y particularmente sobre la cultura Inca, llevan a concluir que hubiera sido altamente positivo el tratar de incorporar el acervo de conocimientos e integrarlos a las disciplinas cientificas especificas. El largo camino de ecología ya había sido recorrido hace siglos.

\section{LA CONQUISTA Y COLONIA: LA DESTRUCCION PARA LA NUEVA ESTRUCTURA DE EXPOLJAGION}

En el período de la conquista y colonia la forma en que América Latina tue "ocupada" por los nuevos dueños se basó en dos falacias

${ }^{18}$ Antúnez de Mayolo, R., Santiago E., La nutrición prehispánica, en Primer Congreso Internacional de Cultivos Andinos. Universidad San Cristóbal-Huamanga/ Irca, Ayacucho, Perú, octubre de 1977, p. 172.

${ }^{10}$ Ver para más detalle: Duccio Bonavía y Roggers Rabines Las fronteras ecológicas de la civilización Andina. En Amaru, No 2, Lima, Perú, 1967. 
fundamentales: la primera, la creencia de que tanto la cultura como la tecnología de los pueblos sometidos eran inferiores y atrasadas con respecto a la europea $y$, la segunda, que los recursos del nuevo continente eran prácticamente ilimitados. De esta forma se justificó plenamente la destrucción y eliminación de las formas y sistemas preexistentes. Además, al considerarse los recursos ilimitados, no hubo mayor preocupación por la tasa de extracción de éstos.

\section{a) Destrucción y colapso demográfico.}

El período colonial de la historia americana se caracteriza por la descomposición de la estructura social y económica de las culturas precolombinas, por la ocupación del espacio por parte de los conquistadores y por el uso de las nuevas tierras. Este uso impuso nuevas formas de organización, introdujo tecnologías, desechó sistemas de producción tradicionales, estableció nuevas estructuras productivas.

La diferenciación en las formas de ocupación del espacio en los sistemas adoptados se explica en función a las diversas estrategias establecidas por el europeo según el rol minero y agrícola de cada región y en particular, en función de la respuesta de los grupos y culturas indígenas. En efecto, el desarrollo social y económico de ciertas sociedades precolombinas y en particular la jerarquización y estructuración del poder de estas sociedades, posibilitaron la utilización parcial de esta organización y estructura $y$, sobre todo, el sometimiento del indio sedentario arraigado a la tierra. Pero, por otro lado el indio nómade, cazador o pescador, con una baja productividad y sin organización social ni costumbre de transferir el excedente, no pudo ser asimilado a un sistema sedentario, lo que produjo su esclavización o el enfrentamiento entre los dominadores y los grupos étnicos que se rebelaron. Esta hipótesis parece explicar la actitud y posición de los europeos, aunque deben tomarse en cuenta factores que dicen relación con la mentalidad española nacida de sus luchas por la expulsión de la clominación árabe que fue transferida a América. Como dice Enrique Florescano20. "Los ocho siglos que duró la reconquista de la península española fueron un antecedente importante, una preparación histórica en la conquista y colonización de las tierras americanas. Cuando los españoles comenzaron a invadir el Nuevo Mundo, emprendieron su conquista con la idea de propagar y defen-

20Florescano, Enrique: Colonización, ocupación del suelo y "fronteras" en el norte de Nueva España, 1521-1750. Tierras Nuevas. El Colegio de México, México, D. F., 1973, p. 43. 
der la fe católica, de extender los clominios de la Corona y ganar fama, honra y riqueza para ellos. La reconquista peninsular les había proporcionado además una ideología que justificaba su expansión: la teoría medieval sobre la justa guerra de cristianos contra infieles"'21.

Aunque hubo áreas y regiones en donde se estructuró una organización social en torno al desarrollo agrícola, en términos generales, primó el sentido "minero" de la explotación. La riqueza "visible" era la minería; los grandes imperios tenían una estructura de explotación en funcionamiento. Para poder apropiarse de esta estructura los conquistadores tuvieron inevitablemente que provocar una catástrofe demográfica, cosa que sucedió en el siglo xvr.

El número de indígenas se redujo abruptamente en toda Latinoamérica, tanto por la sofocación de las rebeliones, por los desplazamientos poblacionales, la desorganización de la producción de alimento y las epidemias. La destrucción y desarticulación de las culturas vencidas turo caracteres de genocidio. Además de la matanza directa, un alto porcentaje murió debido a la introducción del paludismo, sarampión, viruela y fiebre amarilla ${ }^{22,} \mathbf{2 3}$.

Los datos de Denevan ${ }^{24}$ y Parsons ${ }^{25}$, asignaban a América Latina 150 millones de habitantes. Santo Domingo, a la llegada de los españoles, tenía 8 millones, cifra que se volvió a alcanzar recién en 1977 (Cook y Borah) ${ }^{26}$.

En todas partes la disminución de la población aborigẹn fue extraordinariamente abrupta, los nativos parecían morir con el "alimento

${ }^{21}$ Florescano E. cita aqui a Silvio Zavala, New Viewpoint on the spanish colonization of America, University of Pennsylvania Press, Filadelfia, 1943; "The Frontiexs of Hispanic America", The Frontier of Perspective (Walter D. Wyman y C. B. Kroeber, eds.) Madison, the University of Wisconsin Press, 1957, pp. 35-58.

Borah, W. "The historical demography of aboriginal and colonial Latin America: an attempt at perspective". Actas del xxvir Congreso Internacional de Americanistas, 1966.

saral, W. "The historical demography of aboriginal and colonial Latin America: an attempt at perspective", en Population and Economics. Univ. of Manitoba Press, Winnipeg, Canada, 1970.

menevan, W. "The aboriginal population of tropical America", en Population and Economics, P. Duprez ed. Winnipeg, Univ. of Manitoba Press, 1966.

${ }^{25}$ Parsons, J. en "El uso de normas ecológicas paxa el desarrollo en el trópico húmedo americano". IUGN, 1974.

${ }^{2}$ Cook, S. y Borah, W. 1971. Essays in population history: Mexico and the Caribbean. Univ, of California Press, Berkeley. 
de los españoles"27; Cook y Borah estiman una disminución del 90 al 95\% de la población original de América Latina, es decir, un total cercano a 130.000.000 de personas en un período de un siglo28.

En la "tierra caliente" de las costas del Caribe, la despoblación fue completa y donde había montañas contiguas, los indígenas escaparon a un nuevo ambiente (la tierra templada de media montaña). Hoy sobreviven algunas culturas de tierra caliente por encima del piso de café en la Sierra Nevada de Santa Marta, Colombia, como los coguis, araucos y malayos, después de 400 años de adaptación a una oferta ambiental totalmente distinta a la de la preconquista ${ }^{20}$.

Se estima que la población mexicana que habría alcanzado los 16 millones en la época de la conquista, estaba reducida, un siglo después, a cerca de un décimo de ese tota ${ }^{30}$.

En las Indias Occidentales, las poblaciones fueron arrasadas en 50 años y fue necesario importar indios esclavizados del continente.

El Darien de Panamá, hoy despoblado, alojó hasta 800.000 pobladores (Sauer) ${ }^{31}$. El valle del Sinú, en Colombia (Gordon) ${ }^{32}$, y la costa caribe de Costa Rica, también albergaron una población superior a la de hoy día.

En esta declinación, la desintegración social desempeñó un papel por lo menos comparable con la introducción de enfermedades europeas ${ }^{33}$.

"El nadir del número de indígenas parece haber ocurrido en la mayor de las regiones entre 1570 y 1650" (Parsons).

aTParsons, J. "El uso de normas ecológicas para el desarrollo en el trópico húmedo americano". IUCN, 1974.

${ }^{25}$ El colapso demográfico está ampliamente tratado en Galeano, Eduardo, Las venas abiertas de América Latina, Cuarta Edición. Siglo xxr, México, 1973.

${ }^{20}$ Morello, J. "Proyecto de ecodesarrollo, Sierra Nevada de Santa Marta, Colombia". INDERENA-PNUMA, 1976.

${ }^{80}$ Furtado, Celso: La economia latinoamericana desde la conquista Ibérica hasta la Revolución Cubana, Estudios Internacionales, Editorial Universitaria, Santiago, Chile, 1970, p. 21.

"Sauer, C. The man and the ecology of tropical America. Proceedings, 9th. Pac. Sci. Congress. 20: pp. 104-110.

${ }^{a x}$ Gordon, B. L. "Human geography and ecology in the Sinu Country of Colombia". Tberoamericana, 39. Univ. of California Press, Berkeley.

"Sauer, C. O. The early Spanish man. Univ. of California Press, Berkeley, 1966. 
Las consecuencias de la catástrofe demográfica fueron la destrucción de actividades productivas ajustadas al ambiente, la desaparición de la clase de los sacerdotes que tenían el conocimiento empírico más evolucionado y con ellos, de técnicas y tácticas ecológicamente apropiadas.

\section{b) Orígenes de los sistemas de tenencia predominantes.}

La forma utilizada para llevar a cabo este poblamiento y ocupación tiene gran importancia, ya que dio origen a las formas embrionarias de uso de los recursos. Los modos de producción creados trasuntaron los objetivos de las metrópolis.

Mellafe R. ${ }^{34}$ al hacer alusión a los mecanismos de apropiación de la tierra se refiere al hecho de que los espacios cultivados en los primeros años del Virreinato del Perú fueron mucho más reducidos que las fronteras ecológicas del Imperio Incaico. Ello por varias razones. Se abandonaron muchas "tierras nuevas" ganadas a la selva o por la sequía que estaban a cargo de los grupos de mitimaes colocados por los incas, debido al desconcierto provocado por la conquista. Los indígenas tendieron a volver a sus tierras de origen y dejaron las nuevas tierras abandonadas, las que volvieron a ocuparse muchos años después.

Además de este fenómeno la irrupción hispana rompió el aprovechamiento vertical de las economías andinas, desintegrando el autoabastecimiento que existía. El cambio de estructura y la disminución de la población impidieron que las comunidades se ocupasen de áreas más alejadas.

Debido a las razones expuestas $y$, en consecuencia, a la inexistencia de mercados agrarios, al principio no hubo avidez por la acumulación de tierras y posteriormente fue fácil apropiarse de los espacios abandonados. La conquista y la expansión en la época colonial se realizaron en función del financiamiento privado de la empresa bélica combinada con premios, concesiones, atribuciones y privilegios para los conquistadores.

La Huesta Indiana (empresa privada de la conquista) estuvo regulada por el Estado y se basaba en la rápida recuperación del capital invertido. Varias son las complejas formas de retribución de los servicios prestados y tres interesan en particular, pues son el

a'Mellafe, Rolando: "Frontera Agraria; el caso del virreinato peruano en el Siglo xv". Tierras Nuevas. El Colegio de México, México, 1973, pp. 11-42. 
origen de las relaciones técnicas y sociales de la agricultura y del latifundio latinoamericano y, por ende, del uso de los recursos: las mercedes, las donaciones directas y las encomiendas. Las donaciones directas fueron concesiones otorgadas por distintas causas, particularmente retribuciones de servicios de guerra. Es lógico que éstas no se circunscribieran a los lúmites establecidos, sino que, dado el poco control que se tenía sobre ellas, se expandieran y originaran latifundios.

Las mercedes de tierras, con título real, se otorgaron en usufructo con la sola exigencia de que fuesen cultivables. La Corona se reservó la propiedad, pero al pasar de los años estas extensiones fueron cercándose y paulatinamente empezaron a considerarse propiedades privadas. Además, la consolidación de una clase dominante, normalmente interrelacionada entre grupos latifundistas y mineros, sentó las bases para legalizar la concentración de la tierra. La necesidad de transferir los excedentes generados por la tierra influyó en la ausencia de una mentalidad conservacionista.

Las encomiendas se originaron, no en función del usufructo o de la propiedad de la tierra, sino en la asignación de un grupo de indígenas a algún conquistador con el objeto de que éste le sirviera de protección y que posibilitara su educación. La encomienda derivó a la usurpación de las tierras de los indígenas y a la sobreexplotación de ellas, al sometimiento de los indios a un régimen esclavista y, consecuentemente, a la creación de un excedente económico para el encomendero que le posibilitó ascender económica y socialmente.

Hubo variantes sobre estas formas básicas que originaron Ia concentración de la tierra, pero todas ellas tendieron a establecer un sistema señorial que fue la base de la estructuración de clases en Latinoamérica. La declinación relativa de la minería, las transfusiones de intereses minero-agrícolas $y$, sobre todo, el estatus social preferencial del terrateniente, contribuyeron a consolidar esta estructuración.

c) Las estrategias del uso de los recursos.

Es necesario revisar cuáles fueron las principales características de este período, en relación a las actividades básicas en la expansión de ocupación de la tierra en Hispanoamérica y, por ende, en la prioridad del uso de los recursos.

El interés de los españoles en América Latina se centró en las regiones con mayores posibilidades en la explotación de minerales. 
México y la región del Altiplano, Perú y Bolivia, atrajeron las principales empresas y esfuerzos.

El desarrollo de México se basó en la explotación de las minas de plata. Este desarrollo condicionó la ocupación del espacio circundante. J. Arlegui en sus "Crónicas de la provincia de NSPS Francisco de Zacatecas", en 1737 afirmaba: "A todos los minerales ricos que se descubren luego acuden (los españoles) al eco sonoro de la plata... y como el sitio en que descubren es infructífero de los necesarios mantenimientos logran los labradores y criadores de los contornos el expendio de sus semillas y ganados, y como éstos solos no pueden dar abasto al gentío que concurre se ven precisados otros, o por la necesidad o la codicia, a descubrir nuevos labores y poblar nuevas estancias de ganado aun en las tierras de mayor peligro de los bárbaros, disponiendo Dios por este medio que aunque las minas decrezcan, quedan las tierras vecinas con nuevas labores y estancias bien pobladas y con suficiente comercio entre sus pobladores" 35 .

El fenómeno descrito se repitió en México en toda la "faja de plata". Los descubrimientos de minas exigieron producción de alimentos y además tracción animal para que funcionaran los ingenios metalíferos y se trasportaran las provisiones y productos. Esta acción transformó el norte de México subiendo desde el triángulo ciudad de México, Guadalajara y Zacatecas.

En el siglo xvIr el autoconsumo fue la actividad generalizada $y$ base del aumento poblacional. Pero este autoconsumo chocó con la expansión de los cultivos de exportación, los que los hacian normalmente los latifundistas. El autoconsumo tuvo como cultivos principales el maíz y los frijoles.

Las Antillas españolas se orientaron en un comienzo hacia el mercado mexicano en función de la ganadería. Pero, en el siglo xvxrr se produjo una expansión notable por la introducción y el auge del tabaco y del azúcar, especialmente en Cuba. Ya no fue México el destino de la producción sino la Península Ibérica.

Lo sucedido con las Antillas españolas se repitió en toda Hispanoamérica: una forma de orientar la producción desde cada colonia hacia España, sistema que se tradujo en la fragmentación de zonas económicas en que predominaba algún cultivo o rubro dado. Esta especialización económica estuvo en parte influenciada por la notable disminución demogxáfica del siglo xvir que indujo a modificaciones substanciales en el sector agrario. Se descartaron determinados cultivos

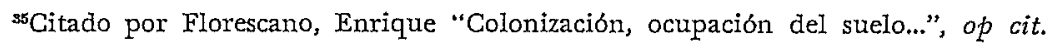


que absorbian mano de obra, por otros más extensivos. Esto sucedió en toda Latinoamérica y fue el primer paso para la creación de una reestructuración social: el reemplazo parcial de la comunidad indígena por la hacienda, la unidad de explotación del suelo dirigida por los españoles.

En América Central el crecimiento económico fue más lento que el constatado en México y las Antillas. En Guatemala, se consolidaron las grandes haciendas y comunidades indígenas fuertemente señorializadas. En Honduras y Nicaragua sólo es dable destacar la ganadería extensiva, y en Costa Rica, en funcion del aporte de los colonos gallegos, se desarrolló, a partir de la mitad del siglo xvint, una agricultura de autoconsumo. El comercio internacional se centró en el único rubro de exportación: el indigo.

En la complejidad de Nueva Granada se entremezclaron funciones económicas y geopolíticas, básicamente por ser el centro del poder militar español. Su principal producto de exportación fue el oro. Su agricultura se orientó al autoconsumo, destacándose el trigo.

Al este, Venezuela mostró en esta época mayor dinamismo e integración. Sus más importantes rubros fueron el cacao, el indigo, el café y el algodón. La costa fue predominantemente plantada con cacao. En la periferia montañosa y los llanos se desarrolló una ganadería que posibilitó exportar mulas y ganado para las Antillas y animales de consumo para la costa.

El Virreinato de Lima basó su economía en la minería, especialmente de oro y plata. Pero los grandes centros mineros en Alto Perú, unidos a las decisiones de separaciones administrativas (Virreinato de la Plata) crearon una economía, particularmente de subsistencia, basada también en la actividad agrícola ${ }^{36}$. Y aquí es dable destacar la diferenciación notoria entre la costa y la sierra. En la costa se siguieron aplicando los antiguos sistemas de irrigación y se realizó una agricultura orientada hacia el mercado hispanoamericano: aguardiente, vino, algodón, azúcar y arroz. La sierra tuvo una doble función; por un lado, atención de los centros mineros y, por otro, agricultura de subsistencia. Esta agricultura se basó en el maíz y la papa y una ganadería muy particular, de camélidos y ovinos. La agricultura tradicional sintió el impacto de las nuevas tecnologías. Como afirma Ponce Sangines, C. .37 "Ia introducción del arado tirado por bueyes,

\footnotetext{
${ }^{30}$ Para más detalle sobre la estructura productiva ver: Santamaría, Daniel, J. "La estructura agraria del Alto Perú a fines del siglo xvirn", Desarrollo Económico, Vol. 18, No 72, Buenos Aires. Enero-marzo, 1979, pp. 579-596.
}

${ }^{37}$ Ponce Sangines, Garlos. La cultura nativa, op. cit. 
con reja de hierro, repercutió en la preferencia para el cultivo de terrenos más o menos amplios y algo llanos que posibilitaban la manipulación, desdeñándose las terrazas erigidas durante el periodo precolombino, dispuestas en los flancos de los cerros y que eran más aptas por su mayor proporción de materia orgánica y en las cuales se empleaba el tirapie". De esta forma se abandonaron las laderas y las terracerías poco a poco fueron desiapareciendo. Posteriormente, al volverse a ocupar, no se respetó esta clara medida conservacionista.

En torno al Virreinato del Perú estaba Quito y la Capitanía General de Chile. La costa quiteña se cultivó con cacao que se comercializaba a través de Guayaquil hacia ultramar. La sierra predominantemente indígena continuó orientada hacia el autoconsumo; en ciertos microclimas se cultivó el algodón y el trigo en las zonas más frias ${ }^{38}$.

Chile tenía actividades, en el siglo xvirr, tanto en su minería como en su agricultura. Amplias áreas fueron cultivadas con trigo que se colocaba en el mercado limeño. La resistencia araucana duró tres siglos y significó para la Corona una inversión de recursos materiales y humanos cuantiosos. El territorio araucano se incorporó considerable ticmpo después de la independencia.

En el Río de la Plata, Buenos Aires canalizó la actividad del crecimiento del litoral y de las tierras de su contorno y Santa Fe. La expansión ganadera de estas áreas se vio limitada por la acción de los indigenas y sólo una parte de la pampa húmeda se trabajó en forma de haciendas.

El este del Paraná en el siglo xvin creció en forma impresionante. La labor de los jesuitas permitió disponer de mano de obra guaraní pacificada. La producción de las misiones se centró en la yerba mate y en el algodón. Después de la expulsión de los jesuitas, Misiones decayó notoriamente y transfirió su anterior auge al Paraguay, al que incluso llegó la expansión ganadera del sureste brasileño.

Las tierras mediterráneas de alta aptitud tuvieron una marcada actividad económica: Cuyo se especializó en la producción de vinos y Tucumán y las áreas contiguas combinaron la producción de cultivos tropicales con una ganadería que servía tanto al Alto Perú como al litoral y Buenos Aires.

Esta es la orientación del uso de la tierra en Latinoamérica en la época de la colonia. Es necesario agregar que la relación hombre-

${ }^{39}$ Mifler, E. V. A.: "Agricultural Ecuador". Geographic Review, Nueva York, 1959, pp. 183-207. 
tierra fluctuó notoriamente y que su distribución fue muy dispar er el espacio y en el tiempo. Desde mediados del siglo xvi la población volvió a expandirse, pero a una tasa reducida. A mediados del siglo xvirr México llegó a tener 3 millones de habitantes y más de 6 a principios del siglo xxx, Nueva Granada llegó a I millón de habitantes a fines del 1700, más de medio millón en Quito y cerca del millón en Chile ${ }^{38}$.

\section{d) La explicación del territorio de los ecosistemas.}

En la conquista y la colonia la estrategia extractiva hacia la metrópoli se centró en la actividad minera. Aunque los cultivos tuvieron gran importancia para el autoconsumo y para la exportación, las superficies cultivadas comparadas con las de hoy día, eran muy limitadas. La demanda para autoconsumo estaba circunscrita a las necesidades de una población muy reducida y la exportación estaba supeditada al transporte y a las limitaciones de la demanda internacional. Hay que recordar que la gran expansiónde la frontera agrícola no se produjo en estos períodos sino que en la segunda mitad del siglo pasado $y$, especialmente, durante el siglo actual.

La actividad agrícola, limitada en superficies, se practicó en torno a los núcleos urbanos y en las plantaciones para exportación. Los sistemas de explotación y el convencimiento de contar con suelo ilimitadamente fueron factores que influyeron en métodos culturales reñidos con la conservación.

Nace la interrogante del por qué se constataron procesos erosivos en áreas que ya tenían agricultura antes de la conquista ibérica. La respuesta hay que buscarla en la integración del medio ambiente que tenían las civilizaciones precolombinas a sus procesos de desarroIlo. EI suelo, el bosque, el agua eran parte integrante de la cultura; conservarlos era prolongar la vida. Para los colonizadores, estos recursos sólo debían servir para cumplir los roles complementarios de la explotación minera.

Cabe además preguntarse el por qué de tantos ecosistemas deteriorados en un período en que el principal proceso de artificialización ecosistémica, la agricultura, era muy limitada. La actividad minera demandaba ingentes cantidades de energía, lo que indujo a utilizar los bosques. Todos los recursos forestales cercanos a las fundiciones fueron consumidos. Las minas fueron abandonadas no porque se

${ }^{30}$ Halperin Donghi, Tulio: Historia Contemporánea de América Latina, Alianza Editorial, Madrid, 1970. 
agotaran, sino por problemas vinculados con volúmenes de agua necesarios para la concentración y con el agotamiento del recurso leña para la fundición.

En el norte chileno la incidencia de la minería tuvo notables repercusiones en las transformaciones del paisaje. Como afirma Pedro Cunill G.40: "Primeramente, en cada mina y trapiche se asolaban los recursos vegetacionales debido a las necesidades del combustible diario y a la alimentación de las bestias. Debido a que con frecuencia se abandonaban estas minas por su agotamiento, el proceso de destrucción de los parajes se iba repitiendo y/o sucediendo intermitentemente ...". Más importante aún fue el despojo de la madera local para uso de las funciones, que se aceleró en el siglo xvir. La localización de estos ingenios de fundición, dispersos y en las proximidades de las minas, explica un acelerado proceso de tala de matorrales $y$ árboles que servían como combustible, especialmente la jarilla (Adesmia atacamensis), algarrobilla (Balsamocarpon brevifolium), algarrobo (Prosopis chilensis).

Poco a poco se pasó de combustible de árboles a leña de arbustales, tolares (la tola de la Puna) y aun a usar pastos perennes como el ichu (Stipa ichu). No hay mina "antigua" en América Latina que no esté rodeada de un halo periindustrial de suelo desnudo sin combustible vegetal o con combustible de muy bajo calórico. Ya en 1516, el prumer Virrey de Nueva España alertaba a su sucesor sobre la brusca cafda de la oferta de combustible vegetal en el valle de México.

El transporte de los productos hacia los puertos o entre poblados se realizaba a tracción animal, por lo que era necesario tener caballos, mulas y asnos. Además el ganado vacuno de origen español ocupó grandes nichos vacíos o semivacíos de rumiantes de alta biomasa. En efecto, desde los trabajos de Simpson, hasta el reciente avance de estudios comparativos de Africa y America, ha llamado poderosamente la atención por sus implicancias en la estabilidad de los pastizales, la ausencia en América Latina de grandes rumiantes pacedores (adultos de $400 \mathrm{~kg}$ a más). El bisonte americano no pasó los límites actuales de la frontera México-usa. Los llanos tropicales tuvieron como únicos rumiantes a los ciervos, y los subtropicales y templados, al guanaco. Ni los ciervos ni el guanaco, ni ningún rumiante, forma-

${ }^{40}$ Cunill Grau, Pedro: "Variables geohistóricas en la destrucción de los parajes geográficos chilenos". En: Encuentro nacional sobre problemas del medio ambiente en Chile. Proyecto cepal-pNuma sobre Problemas del Medio Ambiente en América Latina, 1974. 
ron un eslabón trófico de gran biomasa en las sabanas sudamericanas. Latinoamérica, en cuanto a rumiantes, se caracterizó en el momento de la llegada europea por la dominancia de rumiantes ramoneadores sobre pacedores; por las bajas densidades de hatos, distribución muy laxa de manadas poco numerosas; por la baja biomasa de individuos adultos (150 kg como máximo); y por la muy baja diversidad (10 especies de cérvidos en Latinoamérica frente a 89 en Africa). Recientes estudios en roedoresi1: Dasyprocta, Pediolagus, Lagostomus e Hydrochoerus, indican que en América Latina el grueso de la biomasa de mamíferos herbivoros estuvo representado por roedores de grandes dimensiones. Ellos no ocupan el nicho trófico de los rumiantes, pero tienen comportamientos semejantes a algunos pequeños cérvidos de Africa.

La existencia de nichos vacíos para grandes herbivoros explica la explosiva multiplicación de caballos y burros salvajes y vacunos crioIlos en las pampas del Cono Sur, en el Chaco, en el Pantanal Matogrossense, en los llanos de Moxos de Venezuela y Colombia. Esa ocupación explosiva del nicho por grandes pacedores, especialmente vacunos y caballares, ocurrió no sólo en la llanura sino en el páramo del Macizo de Santa Marta. Estos hatos salvajes de vacuno y caballar crearon un ecosistema seminatural durante la conquista y la guerra contra el indio, a los que se les sumó además, carniceros también introducidos como las jaurías de perros salvajes.

Los vacunos crearon una industria extractiva de carne, sebo y cuero (las "vaquerías"), que se extendió durante dos siglos en la Pampa.

El indígena enriqueció su acervo cultural. A Ios 80 años de introducido el caballo cimarrón, apareció con una espectacularmente rápida y eficiente cultura ecuestre, totalmente adecuada a sus actividades guerreras, con rasgos inéditos de relación jinete-caballo (como domar, conducir, educar y montar). El indio ecuestre, de alta movilidad, incorporó no sólo nuevos elementos de combate, sino élevada capacidad de cazador y de apropiador y manejador de vacuno cimarrón.

$\mathrm{Ni}$ la ocupación de los nichos de grandes pacedores y carniceros por animales ajenos al ecosistema, ni la cultura ecuestre indígena, han sido adecuadamente analizados desde al ángulo relación natura. leza-sociedad. En esa relación hay, en nuestra opinión, la respuesta a muchas incógnitas ecológicas fundamentales sobre ciertos cambios históricos de ecosistemas frágiles latinoamericanos. Por un lado, la

11Estudio del Smithsonian Tropical Research Institute, demuestran que el comportamiento de algunos roedores de América Latina es semejante al de determinados rumiantes africanos. 
desaparición del pulso del fuego en ecosistemas semiáridos, por agotamiento de excedente de biomasa combustible ${ }^{42}$. Por otro lado, la invasión de ecosistemas leñosas en antiguos pastizales chaqueños, caribes y de la Caatinga, y de las sabanas semiáridas de México y Suroeste de USA. Para ello, el vacuno vehiculizó en su tracto digestivo la dispersión de semillas endozoicas. Entre los ecosistemas de instalación en pastizales frágiles, se destacan:

- Los mezquitales y trupillares (consociaciones de Prosopis juliflora) que son invasores de pastizales en USA, México y el Caribe colombiano-venezolano.

- Los huizachales (consociaciones de Acacia Pennatula) de México.

- Los vinalares del Chaco paraguayo-argentino.

- Los fachinales de Acacia, Celtis y Ruprechtia del Chaco y sus equivalentes de la Caatinga.

- Los palmares jóvenes de Copernicia en la Caatinga y el Chaco.

- La moderna expansión del espinillo o ñandubay en el oriente Chaqueño y del caldén en el borde de la Pampa.

Las condiciones clima-edafológicas aceleraron procesos de diseminación, invasión y cicatrización. La eliminación de las culturas caribes y taironas del trópico, fue seguida por una sucesión secundaria de selva rapidísima. Lo anterior ha sido documentado por Gordon, en Colombia, Bennet, en Panamá y Sauer.

En 100 años, en el trópico se reconstituye una selva secundaria de Ochroma (balso), Cecropia (embauba), Cordia y Swietenia (caoba). La rapidez de invasión de la selva en ex cultivos indígenas de yuca y maíz, puede evaluarse pensando que Portobelo en Panamá, estaba con selva secundaria cuando el pirata Dampier esturo allí en 1684, y no quedaba señal aIguna de la ciudad saqueada por Drake 80 años antes.

Mientras tanto, el litoral maritimo no dejaba de ser afectado por la penetración de cazadores y pescadores. Pedro Cunillis en su notable relato ya citado sobre lo sucedido en Chile afirma que a partir de fines del siglo xvII "se comienza a quebrar el equilibrio ecológico

\footnotetext{
${ }^{42}$ Relaciones entre pastizales y leñosas colonizadoras, en el Chaco Argentino. IDIA-INTA, Buenos Aires.

${ }^{43}$ Cunill G., Pedro: "Variables geohistóricas...", op. cit.
} 
por Ia feroz caza del cachalote (Physeter catodon), ballena (Eubalaena australis), ballena azul (Balaenoptera musculus) y otras especies de cetáceos". Hacia 1788 también comenzó la caza de pinipedios y cazadores norteamericanos e ingleses rápidamente arrasaron con los lobos de dos pelos (Arctocephalus australis). Este mismo autor calculat4 que a fines de la colonia entre 1788 y 1809 se exterminaron más de 5 millones de lobos.

En conclusión, la conquista es el disturbio más violento recibido por las sociedades locales y por los biomas de América I.atina. No obstante que el conocimiento del impacto social y ambiental de la conquista ha estado tapado por un velo durante siglos, se ha empezado a hacer lucces y a analizar cuantitativamente el proceso histórico más destructivo de la ocupación blanca de América Latina.

Sobre esa base, es aceptable afirmar que los cambios étnicos, sociales, culturales, ambientales y ecológicos provocados por la conquista son sólo comparables con los ocurridos en los últimos 40 años y son tan y en algunos puntos más importantes para América Latina que este último período en estos aspectos:

- Destrucción de actividades productivas ecológicamente ajustadas;

- Destrucción irrecuperable de recursos culturales;

- Desintegración social;

- Exportación de enfermedades para las que no había mecanismos de defensa coevolutivos (incluso el paludismo);

- Exportación de tramas tróficas nuevas de enorme impacto en biomas de pastizales (vaca, caballo, perro, cabra, oveja, porcino);

- Destrucción de bosques y selvas.

Los resultados de esa acción en los ecosistemas fueron:

- Cambios extensos de cultivo a selva;

- Cambios extensos de pastizal a arbustal;

- Aparición de ecosistemas o partes de ecosistemas inéditos como la mediterraneización del valle central de Chile, de la Pampa argentina-uruguaya-brasilera, en cuanto a cultivos y malezas.

\footnotetext{
"En base a los antecedentes dados por Pereira Salas, Eugenio, en su estudio "Los primeros contactos entre Chile y los Estados Unidos", I97I.
} 


\section{DESDE LA FORMACION DE LOS NUEVOS ESTADOS} FIASTA LA GRISIS DE 1930

a) Caracteristicas del periodo.

Las guerras napoleónicas produjeros tal remezón en la estructura de los imperios ibéricos que fueron fundamentales para poner fin a la era colonial. Además, las profundas transformaciones económicas sufridas en Europa en el siglo xvir incidieron en un cambio sustantivo en las relaciones de poder de los imperios. La apertura de nuevas áreas al comercio internacional posibilitó la acumulación de recursos financieros, lo que pavimentó el camino de la Revolución Industrial.

Las colonias, crecientes y algunas pujantes como Nueva Granada y Río de la Plata, necesitaban mercados para sus exportaciones e importaciones de productos manufacturados. EI mercantilismo europeo por sus barreras proteccionistas impedía la importación de productos latinoamericanos. Por otra parte, España no proporcionaba los productos manufacturados que las colonias necesitaban. La estructura del Imperio Español, que se había formado en torno a la explotación minera, no había podido readecuarse pese a los esfuerzos realizados tanto en la reforma económica como en la política administrativa. $Y$ así, rápidamente las colonias entraron en movimientos de liberación.

Además en la independencia iberoamericana influyó notoriamente el surgimiento de una burguesía, básicamente mercantil, europeizante, que "pretendió liquidar el pasado precolombino y colonial y que buscaba integrar las distintas regiones en las corrientes del comercio internacional en expansión" ${ }^{\prime 4}$.

Al respecto Sunkel y Paz afirman que "la penetración de la RevoIución Industrial a través de un sector especializado de exportación conforman un crecimiento de naturaleza diferente; ... Trátase siempre de una actividad que descansa sobre la exportación de ciertos recursos naturales con que ha sido favorecida determinada nación" ${ }^{46}$.

Aquí se centra la característica fundamental de este período: el esfuerzo de las nuevas naciones para incorporarse al intercambio

${ }^{15 E}$ En relación a este tema Celso Fuirtado cita a Arturo Urquidi Morales, "Las comunidades indígenas y su perspectiva histórica" en Les problèmes agraires des Amérique Latines, Paris, 1967, quien destaca el espíritu europeizante de los lideres de la guerra de la independencia. $O p$. cit., pág. 37.

${ }^{46}$ Sunkel, Osvaldo y Pedro Paz: El subdesarrollo latinoamericano y la teoría del desarrollo. Siglo xxr, México, 1970. 
internacional en base a la oferta de recursos naturales. Las economías, entonces, estuviercn estrechamente ligadas a las frecuentes y violentas variaciones que experimentaron los mercados mundiales de productos básicos. Sunkel y Paz afirman: "Las interrelaciones estructurales entre el sector exportador y las actividades productivas más importantes y modernas del sistema económico establecen así una estrecha relación entre la inestabilidad de la actividad exportadora y el resto de la economía" 47 .

De esta manera, el trato dado a los recursos naturales sufrió los avatares de estas inestabilidades. La apropiación de los recursos productivos por propietarios nacionales, en general, no influyó mayormente para que el tratamiento de los recursos siguiese siendo "minero". En épocas de auge las posibilidades de enriquecimiento a corto plazo supeditaron una tasa de extracción deteriorante.

\section{b) Podery recursos naturales.}

El nuevo poder se estructuró en torno a la posesión de los recursos naturales: tierra y minas.

En Perú, Bolivia y México el poder del Estado fue predominantemente minero. Perú y Bolivia paulatinamente integraron el poder de la minería con el de la tierra. Sólo México hizo excepción, la que se manifestó en la profunda inestabilidad política del siglo pasado. En las economías mixtas como la chilena las burguesías también siguieron el camino de la integración minero-agrícola. En Chile, la Constitución de 1833 había entregado la totalidad del poder del Estado a la fracción latifundista, pero progresivamente el sector minero, en función del excedente generado, fue invirtiendo en la agricultura principalmente por la compra de haciendas.

En consecuencia, salvo el caso mexicano, el poder se estructuró o en torno a la agricultura o en función de los acuerdos o la integración entre los grupos agrícolas y mineros. Este hecho fue sumamente importante en la ocupación del espacio y en la forma de intervención a Ios ecosistemas, ya que los grupos latifundistas trataron los recursos de acuerdo a las perspectivas pólítico-económicas. Pero, la fuerza del poder estatal no fue homogénea y centralizada. En el orden interno de cada país, hubo presiones y lucha para establecer el dominio de una región sobre otra. Dos factores básicos incidieron en ello: por un lado la importancia económica de una región con relación a las

*Tbid, p. 64. 
otras y, por otro lado, la posición espacial de la región como canalizadora o acopiadora de las producciones de las otras. La obtención de una mayor importancia económica dependió, en consecuencia, de la posibilidad de exportación; así Perú no tuvo mayores problemas, pero Colombia se debatió en luchas intestinas. La ubicación del puerto de Buenos Aires fue fundamental para establecer el dominio de la zona litoral.

La reestructuración del poder tuvo una serie de tropiezos debido a las dificultades para reorganizar un sistema productivo acorde a las nuevas inserciones en el mercado internacional. En este sentido la presencia inglesa, de gran importancia en la ruptura independentista, en el período naciente de las nuevas repúblicas, se tradujo en la penetración de sus intereses $y$, por ende, en la formación de los primeros vínculos de dependencia. Estos vínculos fueron estrechándose cada vez más, de manera de crear sistemas de producción acorde a la evolución del desarrollo industrial inglés.

La historia de los cambios políticos latinoamericanos está íntimamente relacionada con el auge de determinados productos fundamentales que generaban el excedente económico4s. Así, en Venezuela, la hegemonía conservadora sucumbió debido a la crisis cafetalera. En Guatemala surgió un nuevo estilo político cuando se desarrolló la cultura cafetalera. Honduras y Nicaragua dependieron del poder generado principalmente de la activiclad ganadera; El Salvador de la explotación del índigo; México, después de su liberación y pese a sus amplios recursos mineros, no pudo superar la crisis del algodón y el país se debatió en largas luchas intestinas. En Costa Rica la estabilidad política se organizó en torno a una clase media de productores cafetaleros, los que resistieron cualquier intento de intromisión militar y sentaron las bases de una democracia estable.

Países como Ecuador, Colombia, Brasil, parte de México y Venezuela y los de América Central y el Caribe, tuvieron comportamientos disimiles de acuerdo a las variaciones de productos tropicales. Al azúcar y tabaco de sigilos anteriores se agregó la expansión del café y del cacao. Los cultivos tropicales sirvieron para efectivizar la ocupación económica de los territorios, pero sus formas de inserción en las economías de los países variaron notablemente. En Brasil, los productos tropicales jugaron un rol importante en el desarrollo; la estructura social dependió de su organización y los sectores de comercio y servicios se organizaron en torno a la actividad agrícola. Pero

"sPara más detalle ver: Di Filippo, Armando: Raices históricas de las estructuras distributivas de América Latina. Cuadernos de Ia CEPAL, No 18, Santiago, Chile, 1977. 
en otros países, especialmente los centroamericanos, la organización de los cultivos de exportación combinó formas de inserción en la estructura económica y de enclaves. Estas no dinamizaron el desarrollo y movieron flujos de excedentes hacia los paises centro.

La ampliación de la frontera agrícola de todos estos países, en particular en la primera mitad del siglo pasado, fue limitada. Los cultivos tropicales ocuparon una reducida porción de los suelos agrícolas, generalmente en el entorno de los puertos de embarque. Las áreas subtropicales y templadas se organizaron normalmente en haciendas y la ganadería fue una actividad fundamental. La penetración hacia las regiones tropicales casi no se produjo y las selvas sólo sirvieron como fuente energética.

Perú desde mediados del sigịo pasado dependió de su nueva riqueza: el guano. Al lado de esta explotación puntual el país entraba en un proceso de liquidación de las comunidades de tierras. Las haciendas de la costa continuaron generando excedentes a partir del azúcar y del algođón. A la clecadencia del guano siguió el auge del salitre en el sur.

La guerra del Pacífico consolidó la posición chilena y creó graves problemas a la economía peruana. Los sectores mineros chilenos, casi sin conflictos, innovaron en una sociedad hegemonizada hasta ese entonces por los latifundistas de la zona central. El auge salitrero, la apertura creciente del mercado internacional y la ausencia de contradicciones básicas entre los grupos económicos dominantes, hicieron de Chile un país de crecimiento sostenido y de estabilidad política, sólo rota en 1891 en la corta guerra civil que culminara con el suicidio del Presidente Balmaceda ${ }^{49}$. El poder se había estructurado en torno a los latifundistas y la importancia relativa de éstos fue siempre mayor que lo que se le hubiera asignado por su control en la economía.

Guba seguía siendo colonia de España y su economía se basaba cada vez más en el azúcar. Sus nobles bosques eran progresivamente devorados para producir la energía necesaria de los ingenios. La mano de obra, siendo esclava, le permitía resistir los avatares del mercado:

En el resto del Caribe, la agricultura de exportación siguió centrada en el azúcar y en menor medida en otros cultivos tropicales.

El auge del café influyó notoriamente en las zonas de aptitud para

\footnotetext{
10Para más detalle ver: Cariola, Carmen y Sunkel, Osvaldo: Expansión salitrera y transformaciones socioeconómicas en Chile: 1880-1930. chacso y Joint Committee of Latin American Studies, Santiago, Chile.
} 
cultivarlo como las de Brasil, México, Colombia, Venezuela, El, Salvador y Guatemala. El ciclo del café estuvo ligado al problema de la demanda y también a las especulaciones del sector intermediario y financista. En 1906 Brasil estableció un sistema preventivo contra la sobreproducción, que aunque impidió una quiebra total, estabilizó el precio a un nivel bajo. Las experiencias deI Instituto del Café y el cúmulo de contrastes experimentados sentaron las bases para que el sector latifundista se dedicara a crear una organización de mercado para sus productos. Esto posibilitó la consolidación de una estructura de poder cimentada en la unión de los terratenientes.

En Argentina y Uruguay, al crecimiento del ganado se unió el trigo y el maíz, que fueron los cultivos básicos de la expansión cerealícola. El espectacular crecimiento de los ferrocarriles hizo incorporarse a Santa Fe y al sur de Córdoba a estos cultivos. En 1870 habían sólo $732 \mathrm{~km}$ de ferrocarril; en 1890, sólo 20 años después habían subido a $9.254 \mathrm{~km}^{50}$. El comercio de cereales fue dominado por pocas firmas exportadoras. Los intereses comerciales unidos a los grupos financieros de Buenos Aires hegemonizaron esta expansión. Los núcleos ginaderos, particularmente de la provincia de Buenos Aires, mantuvieron sus influencias y peso en la estructuración del poder político.

Estos grupos terratenientes tuvieron un excedente tal que les permitió hacer inversiones para las innovaciones tecnológicas: los principales, apotreramiento y mejoramiento animal. Las exccpcionales condiciones ecológicas de la pampa húmeda y la estrucu:ración de un sistema de propiedad, el latifundio ganadero, que por úfinición subutiliza los recursos, impidieron el deterioro que se dio en otros rubros como el café. Pero debe señalarse que en las zonas periféricas de la pampa la explotación ovina ya en el siglo pasado habia tenido efectos selectivos deteriorantes.

A principios de siglo surgieron cultivos importantes para la estructuración social, económica y política. En las zonas bajas y húmedas de Centroamérica, en Honduras, Nicaragua, Guatemala, Costa Rica y Panamá y en Sudamérica, en Ecuador Colombia y Venezuela, el banano se expandió notablemente y llegó a ser el principal producto de exportación de varios países centroamericanos. La efímera explotación del caucho, como se verá más adelante, también se incorporó temporalmente como un producto de exportación. Otro rubro importante

${ }^{50}$ Cortés Conde, Roberto, "Patrones de asentamiento y explotación agropecuaria en los nuevos territorios argentinos (1890-1910)", Tierras Nuevas. El Colegio de México, 1973, pp. 105-120. 
fue el tanino extraído de la explotación del quebracho colorado, principalmente en el Chaco.

La evolución de la estructura productiva latinoamericana influyó en el auge o decadencia de la hegemonía de determinados grupos de terratenientes, en su capacidad para detentar parte del poder en las transacciones políticas con otros sectores de la economía como la minería o con el capital financiero y con los comerciantes y exportadores. Esta capacidad de negociación o dominio tuvo sus bases en los sistemas y formas de tenencia de la tierra originados desde la conquista y cuya evolución y consolidación se realizó a lo largo de la colonia y del período postcolonial de las naciones independientes.

Es evidente que dentro del marco histórico que se está exponiendo la estructuración de la tenencia se consolidó en Latinoamérica en torno a las formas Iatifundistas. Esta "constituyó el sistema básico de dominación social apoyado sobre tres elementos: el monopolio señorial sobre la tierra agrícola, la idleología paternalista de la encomienda y el control hegemónico sobre los mecanismos de intercambio poder y representatividad"

c) Acción antrópica en los ecosistemas latinoamericanos.

La ocupación del espacio latinoamericano y la forma que se usaron los recursos naturales fundamentalmente agrícolas siguieron afectando en mayor o menor rscidida los ecosistemas latinoamericanos.

Una carar :̌ıstica fundamental fue la penetración: esta se hizo preferentemente desde el litoral, sea marítimo o fluvial, hacia el interior. Esta norma tiene varias excepciones. Los centros mineros se explotaron independientemente de la lejanía de la costa. Además, algunas áreas de climas templados o incluso subtropicales, pese a estar a gran distancia de la costa, se poblaron y explotaron. Es el caso de las áreas en torno a las ciudades españolas como Tucumán, Salta, Santiago del Estero, Górdoba, etc.

Otra característica relevante de la intervención de los ecosistemas es que ésta se realizó preferentemente en áreas templadas. Puede señalarse a este período como el de la modificación e intervención de los ecosistemas templados. La intervención tropical se limitó al área de influencia de las costas y a la implantación de enclaves ecológicos con el algodón, café, cacao, azúcar.

¿a organización y los sistemas de la agricultura tuvieron mucho

"García, Antonio: Dinámica de las reformas agrarias en América Latina, IGIRA, Santiago de Chile, 1969, p. 7. 
mayor ingerencia que la minería en la estructuración social y ocupación dél espacio. El crecimiento de la industria minera de exportación estuvo asociado a la desnacionalización de la misma, por lo que se desarrolló, en la mayoría de los casos, en sistemas de enclaves.

Pero clonde se desarrolló la minería, todos los recursos forestales de la periferia se talaron para ser usados en las fundiciones. Además todas las áreas de praderas se sobreexplotaron debido al sobrepastoreo que ocasionaron los mulares, asnos y caballares.

En Chile, al desarrollo minero se asoció el auge de una agricultura privilegiada en cuanto a sus posibilidades de mercado en el Pacífico. Además, el auge del salitre creó un polo interno de demanda de los productos del sur. Esto condicionó la continua expansión de los cereales, particularmente el trigo. Amplias áreas se incorporaron a este cultivo más allá de la aptitud real del suelo. Toda la cordillera de la costa hasta la frontera araucana del sur se sobreexplotó, erosionándose gravemente. Los trastornos ecosistémicos iniciados el siglo pasađo aún persisten.

Los araucanos habian sido la barrera inexpugnable que contenían el avance hacia los densos y ricos bosques del sur de Ghile. Sólo pequeños caseríos y misiones habían penetrado al sur de Valdivia desde los fuertes. Más de trescientos años de lucha habían servido para preservar el nicho ecológico de este grupo étnico. La penetración de la "civilización" se realizó con las enfermedades y el alcohol en una población ya muy reducida. La colonización alemana penetró por el sur y fue "preparada" limpiando el bosque para hacer agricultura. El gran naturalista Claudio Gay escribía al respecto, en 1852:" ".. no se encontró más recurso que el de preparar el territorio de Llanquihue (una provincia chilena), desembarazado de la mayor parte de sus selvas por un incendio que había durado más de tres meses" $"$ 2 . En 30 a 40 años desaparecieron cientos de miles de bosques de especies nobles como alerce (Fitzroya cuppressoides), araucaria (Araucaria araucana), varias especies de hayas o robles (Nothofagus sp.). Además raulí, canelo, olivillo, etc.

Bolivia basó su desarrollo en tres procesos sucesivos que dependieron directamente de la disponibilidad de los recursos naturales: primero, el desarrollo de la minería de la plata, ya analizada en el período colonial; segundo, la constitución de la gran propiedad agropecuaria del siglo xix y, tercero, el desarrollo de la minería del estaño

${ }^{59}$ Gay, Claudio. Agricultura chilena. Instituto de Capacitación e Investigación en Reforma Agraria, rcreA, Santiago de Chile, 1973. (Edición original: 1862). 
desde comienzos del siglo $\mathrm{xx}^{53}$. La gran propiedad boliviana que no estuvo ligada al régimen agroexportador significó la destrucción del régimen de comunidades. Esta destrucción tuvo notorias repercusiones en el Medio Ambiente. Los sistemas del productor de comunidades altiplánico, que habían heredado tecnologías precolombinas de manejo y conservación de los recursos, fueron desplazados por las técnicas europeas de labranzas y de manejo de ganado. Los frágiles ecosistemas altiplánicos, altamente vulnerables a la acción antrópica, rápidamente se deterioraron. Las condiciones semiáridas de ellos convirtieron a muchas áreas en zonas con procesos crecientes de desertificación. La gran propiedad, al hacer dependiente a los pequeños agricultores y apropiarse del excedente que generaban, los obligó a sobreexplotar el suelo. La fauna autóctona de camélidos tuvo que compartir sus recursos forrajeros con los ovinos y en algunas regiones con los caprinos. Las vicuñas fueron diezmadas debido a la alta cotización de su lana. A principios de este siglo esta especie ya podría considerarse en vías de extinción.

Al respecto no puede dejar de mencionarse la continua depredación que se realizó por efecto de la caza indiscriminada. Toda América Latina fue afectada en la eliminación de muchas especies. Según Federico Albert54 entre 1895 y 1900 se exportaron 1.685 .400 pieles de chinchilla en el Norte Chico chileno; hoy día esta especie sólo se cría en cautiverio.

En Perú, las áreas altiplánicas sufrieron un proceso similar al boliviano. En la costa, los cultivos de azúcar y la explotación del guano, aunque más puntuales, ocasionaron un impacto de acorde con la intensidad que se realizaron.

La incorporación de los suelos de la pampa húmeda a la ganadería se produjo bastante tiempo después de la independencia. Basta citar que en 1872 la superficie cultivada (preferentemente con cereales) era de sólo 600.000 hectáreas. Antes, las extensas pampas húmedas y semiáridas estaban pobladas por: ganado vacuno cimarrón. Este se reproducía libremente y continuaba diseminando las nuevas especies forrajeras. La presión indígena hacía a su vez limitar la actividad agropecuaria. En 1875 la línea de plazas fortificadas aún estaban dentro de lo que hoy es la provincia de Buenos Aires.

En aquella época se fijó el concepto de frontera agropecuaria: el

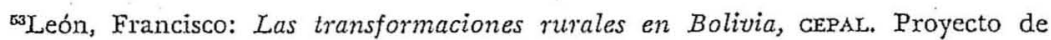
Desarrollo Social Rural. Santiago, Chile, octubre de 1977. (Borrador para discusión).

"Albert, Federico. "La Chinchilla". En Anales de la Universidad de Chile, 1900. 
límite entre las colonias de europeos (casi todas españolas) y las tierras de los indios libres. Hasta fines del siglo xix tanto a un lado como al otro la actividad básica era la ganadería. A un lado, la cría extensiva, al otro, la taza del ganado salvaje.

La pampa sufrió la paulatina transformación del pastoreo. En la pampa semiárida el efecto del sobrepastoreo se dejó sentir rápidamente, predominando una vegetación de gramíneas xerofíticas y de baja densidacl. En la pampa húmeda los sistemas de quemas y las plantas introducidas contribuyeron a transformar la vegetación. Se propagaron muchas gramineas europeas y africanas. (Poa sp, Cynodon sp, Panicum sp, Pennisetum, Digitaria sp, Lolium sp, Avena sp, Hordeum sp), así como alfalfa. Las transformaciones alcanzaron también a la fauna. Los pacedores continuaron reemplazando y expulsando al guanaco, ñandú y ciervo.

En la banda oriental, en Uruguay, la pampa sufrió las mismas transformaciones pero más lentamente. La tradición ganadera fue mayor aquí que en Argentina; sólo en 1860 se empezaron a sembrar. los primeros cultivos de trigo y maíz por colonos suizos.

$\mathrm{El}$ interior argentino y particularmente sus antiguas ciudades españolas se convirtieron en polos de desarrollo basados en sus regiones naturales. Las provincias de Mendoza y San Juan continuaron desarrollando la viticultura y fruticultura. Tucumán siguió durante el siglo xIx siendo el gran productor de mulares para el transporte $y$ ganado vacuno; pero sus excepcionales condiciones climáticas hicieron esta provincia productora de caña de azúcar. Santiago del Estero fue siempre la provincia de tránsito. Tal como afirma Thomson, B. "al no poseer atributos ambientales se estanca, ya que no constituye ecológicamente espacio apto para la expansión de la pampa húmeda"55. En Córdoba también tuvo auge la cría del ganado mular para los mercados mineros de Perú que se enviaban vía Salta.

La Patagonia austral, poblada por indios tehuelches y onas ( $y$ en menor medida por alacalufes y yaganes) se mantuvo como territorio virgen hasta mediados del siglo pasado. Su desarrollo comienza con el auge de los yacimientos auríferos, los que se agotaron muy pronto. A fines del siglo pasado se introdujo el ovino, que cubrió rápidamente todas las áreas esteparias. El difícil equilibrio ecológico en una región de escasa temperatura, con suelos muy delgados, con vientos intensos y continuos, con escasa precipitación y con una regetación predomi-

\footnotetext{
"Thomson, Brian. Periferia y medio ambiente: tres casos en Argentina y Brasil (1870-1970). En Revista Internacional de ciencias sociales, Vol. $x x x$ (1978) No 3, unesco. París, pp. 531-568.
} 
nantemente herbácea acorde a estas condicionantes, fue rápidamente alterado por la acción selectiva del ovino.

En Brasil es donde más denotó la penetración de las áreas de climas templados. A mediados del siglo xix el sudeste de Brasil sólo estaba ocupado en los litorales marino y fluvial.

A partir de esta fecha comenzó el movimiento de la frontera en función de colonizaciones europeas y locales. Ya a principios de este siglo parte importante de los Estados de Rio Grande do Sul y Santa Catarina se habían colonizado y empezaba paulatinamente a desplazarse la explotación cafetalera de São Paulo al interior y a la parte norte de Paraná $\overline{6}$.

A este respecto, refiriéndose a la época de fines de siglo, Tulio Halperín Danghi afirma: "En Brasil el café avanza sobre tierras nuevas, cuya fertilidad agota; la zona cafetalera es una franja en movimiento que deja a su paso tierras semidevastadas; ya en el momento inicial de la expansión paulista, zonas enteras del Estado de Rio de Janeiro llevan la huella de una prosperidad pasada para siempre junto con el vigor de la tierra que la explotación cafetalera agota sin piedad" 57 . Los márgenes amplios de la frontera agrícola cafetalera posibilitaron esta expansión por un largo lapso sin que se mellara el poder de los grupos hegemónicos.

En el nordeste la acción del hombre agravó considerablemente la consecuencia de las secas. La fragilidad de esas áreas áridas, intervenidas ya el siglo pasado por sobrepastoreo, se vio agravada por sequías extremas. Esto creó serios problemas a áreas más húmedas de la costa o de la serranía por la emigración masiva de la población. (Sólo entre los años 1877 y 1879 emigraron del Estado de Ceará cerca de 150.000 personas a las que se les llamaba "flagelados" o "retirantes"'ss.

Ya a fines del siglo pasado todo el polígono de las secas presentaba grandes extensiones con notorios procesos de erosión y además con una vegetación deteriorada.

El caucho se explotó intensa y efímeramente en la Amazonia. Fue una explotación silvestre cuya decadencia se produjo debido a la mayor productividad y menor costo de las plantaciones de Malaya e Indias Holandesas. En Ecuador, Perú, Venezuela y Golombia los sistemas más primitivos que los realizados por los "siningueiros" brasi-

${ }^{3 \sigma}$ Ver Thomson, Brian: Periferia y medio ambiente, op. cit.

${ }^{57}$ Halperín Danghi, Tulio. Historia contemporánea de América Latina, op. cit.

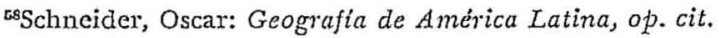


leños tuvieron nefastas consecuencias por la afectación de grupos indigenas y la destrucción de los árboles.

El caucho natural lo produce él árbol Goma de Pará (Hevea brasilensis) que es de primera calidad y Castilloa elástica que es de calidad inferior. A fines del siglo pasado entre 1890 y 1910 esta actividad atrajo a más de medio millón de habitantes. La explotación de Hevea brasilensis (efectuada por "singueiros") no afectó mayor. mente a los árboles debido a que a éstos se les sometía sólo a una sangría. Mientras que la explotación de Casilloa elástica produjo serias alteraciones ya que los "caucheros" debían cortar el árbol. Cuando el caucho declinó la población se restableció y la selva cubrió sus claros con especies cicatrizantes.

Más al norte, en Venezuela, a mediados del siglo pasado, se creó un sistema de ocupación de suelos agrícolas itinerantes de gran impacto en la conservación de los recursos. El "sistema de Conucos" se originó después de la abolición de la esclavitud y al final de la cruenta guerra social[59. El desplazamiento de los campesinos de un lugar a otro, como forma de agricultura itinerante de subsistencia se basó en la utilización de los nutrientes de la vegetación que se incorporaban al suelo mediante la roza y/o quema. De esta forma se aprovechaba y cosechaba largos procesos de evolución ecosistémica. Aunque en estas áreas la agricultura nunca se desarrolló e intensificó, esta agricultura móvil fue muy deteriorante para el medio, pues se basó en un sistema absolutamente al margen de cualquier medida de conservación.

En los llanos el ganado se reprodujo libremente a similitud de lo sucedido en la pampa húmeda, con la diferencia que la apropiación de rebaños creó el sentido de propiedad territorial de los 1 lanos ${ }^{60}$.

Mréxico, después de la independencia, presentó un ritmo de trans. formaciones que afectó los variados ecosistemas que posee. El norte árido continuó el lento proceso deteriorante de la ganadería extensiva, agravado por sequías extremas.

La península de Baja California fue poblada en la segunda mitad del siglo pasado por latifundistas que intensificaron las explotaciones ganaderas. Al sur volvió la caña junto al plátano, palmas, cocoteros

${ }^{5}$ Di Filippo, Armando, Raices históricas..., op. cit

${ }^{\infty}$ Carrera Damas, Germán, "Sobre el alcance y el significado de las polfticas agrarias en Venezuela durante el siglo xIx". Tierras Nuevas. El Colegio de México, México, 1973, pp. 121-138. 
y mangos. Muchas minas se abrieron repercutiendo esto en Ios escasos recursos leñosos.

En la meseta central la pérdida de las tierras indígenas en manos de latifundistas se tradujo, ya a mediados del siglo pasado, en una expulsión de éstos hacia hacia áreas marginales. Es. en esta área donde se manifestó con fuerza los procesos erosivos agravados por las condiciones climáticas.

La llanura entre el Golfo y la Sierra Madre Oriental siempre atrajo Ia atención por la riqueza de sus recursos naturales. EI "frente de agua" o Anáhuac fue siempre dominado y celosamente guardado por pueblos invasores. La sal y el algodón, que eran los principales productos que los Huaxtecas enviaban al centro, siguieron a fines del siglo xux produciéndose, pero eclipsados por el petróleo. Los Huaxtecas, otro gran pueblo defensor de su "nicho ecológico", tuvieron que retirarse definitivamente en función de la penetración de intereses de alta influencia y poderío.

En la península de Yucatán la intervención ha significado la explotación de las maderas preciosas de sus selvas. A comienzos de siglo aún vivían en territorio mexicano algunos grupos de indios libres.

Gentroamérica hay que dividirla en su zona atlántica y pacífica. Las condiciones tórridas de la primera sirvieron de freno a la penetración irrestricta de este territorio. En el Pacífico la situación fue diferente, pues aquí se introdujeron mayoritariamente los cultivos tropicales.

La historia de las islas del Caribe sigue las particularidades propias de su relativo aislamiento en un marco diferente dada la diversa influencia inglesa, española, francesa y holandesa.

En una misma isla, Haití, la separación en sus dos zonas culturales y los propios movimientos libertarios se tradujeron en una relación hombre-tierra muy diferente $y$, en consecuencia, en un trato dado a los recursos también diverso.

\section{A MODO DE EPILOGO}

Hemos tomado algunos aspectos relevantes que se han considerado básicos para poder interpretar pasajes de la historia de Latinoamérica desde una dimensión ecológica.

No hemos avanzado más allá de comienzos de siglo debido a la complejidad del tema. La explosión demográfica, la crisis del 30, el conflicto mundial último, las readecuaciones del mundo capitalista, 
los impactos del progreso científico y tecnológico, la creciente importancia de la energía, etc., son procesos y problemas tan amplios que escapan de las posibilidades de estas notas.

Queremos plantear algunos aspectos que deben reflexionarse.

La pérdida de casi todo el acervo cultural precolombino, se ve agravado hoy día por el conflicto entre lo "moderno" centrado en un estilo de desarrollo en ascenso y to "tradicional". Mucho de lo tradicional contiene la amalgama de este conocimiento precolombino con tecnologías y sistemas implantados por los colonizadores.

El costo en vidas humanas y en recursos, muchos de ellos desapercibidos, para poder implantar el "estilo de desarrollo" ibérico, fue realmente impresionante. La penetración del estilo se realizó en función del desplazamiento del estilo anterior. Se utilizaron las estructuras de poder, la estratificación social, los grupos y castas preexistentes para poder consolidar las nuevas formas de poder ascendentes.

El largo períoclo colonial se identificó con una explotación "minera" de los recursos naturales de América Latina. Todo hacia la metrópolis o hacia "el centro". La metrópolis sólo debió implantar una organización social a veces armónica, casi siempre represiva, que ¿c asegurase el flujo de excedentes.

En el periodo de las naciones independientes hubo un esfuerzo para vertir las ventajas obtenidas de la posesión de los recursos naturales hacia el desarrollo de ellas. De todas formas los esfuersos chocaron con las formas imperialistas del momento.

Pese al esfuerzo por reencontrar las vías de desarrollo en el patrimonio de cada una de las naciones, los principales modos de producción siguieron atentando contra la conservación de los recursos. En realidad, la concepción de la disponibilidad casi ilimitada de ellos no predispuso para proyectar a largo plazo el deterioro a que se les sometía.

El desconocimiento en América Latina de sus ecosistemas y de sus funcionamientos aceleró procesos de deterioro que bien podrían haber sido aminorados o evitados. Este desconocimiento se remonta a la eliminación de la "inteligencia" cuando los conquistadores llegaron a América.

Aunque si este conocimiento hubiese existido, el aporte hubiese sido limitado si no se hubiera conceptualizado la relación sociedadnaturaleza, no sólo desde el punto de vista tebrico sino tratando de interpretar los casos concretos que se dieron.

Por último, cabe reflexionar si nuestra historia no es sino la historia de la tasa de extracción de nuestros recursos, de las formas foráneas 
de dominación, de las estrategias y las tácticas de penetración del estilo ascendente, de la fuga de excedente extrarregión, de la ampliación de la frontera, etc. Si esta es nuestra historia, cabe reflexionar cuáles serán las transformaciones de la ecología del paisaje y cuál el grado de afectación y deterioro de los ecosistemas, si cada día aumenta la población y las necesidades, si la tasa de extracción se acelera, si se consolidan formas de penetración del capital foráneo, si el nuevo estilo depredador se intensifica. 